\title{
Effectively Assessing Professional Engineering Skills
}

\author{
David S. Strong \\ Professor and NSERC Chair in Design \\ Engineering \\ Faculty of Applied Science \\ Queen’s University, Kingston, Ontario \\ strongd@ilc.queensu.ca
}

\author{
Sue Fostaty Young \\ Doctoral Candidate and Teaching Fellow \\ Faculty of Education \\ Queen’s University, Kingston, Ontario \\ fostatys@educ.queensu.ca
}

\begin{abstract}
This paper outlines the assessment dilemmas and challenges that were experienced by faculty members and students alike during initial iterations of APSC 190 (a first-year, professional engineering skills core course in the Faculty of Applied Science at Queen's University) and how the adoption and implementation of the ICE model of assessment [1], [2], [3] served to address those challenges. ICE, an acronym for Ideas, Connections and Extensions is based on cognitive/transformation theories of learning similar to those put forth by Biggs' and Collis' SOLO taxonomy [4], and describes learning as a process of growth from novice toward expert. Unlike SOLO, ICE was intentionally designed for use in the classroom by teachers and students. The simplicity of the model increases its utility and portability to a host of learning activities and furnishes an accessible vocabulary and framework to facilitate communication about expectations for learning. The paper includes an overview of the ICE model, suggestions for implementation and the effects and limitations of the model for use in professional skills courses. Current-use examples are provided that illustrate the model's utility and its implications for shaping student learning.
\end{abstract}

\section{Introduction}

In addition to valuing and teaching mathematics, sciences, and other topics typically referred to as the "hard skills", Faculties of Applied Science and of Engineering have recognized the necessity and desirability of including professional skills education as integral to degree engineering programs. These complimentary skills (often inappropriately referred to as "soft skills") have been identified as critical to students' future success as practicing engineers and therefore deserving of the time and attention required to teach (and assess) them well. While professional skills have been high on the list of engineering employer's surveys for many years, the need for graduating students to be proficient in these skills is growing with industry globalization and the resultant availability of low cost, technically capable off-shore engineering services.

The Canadian Engineering Accreditation Board has yet to revise their accreditation criteria with specific professional skills capability requirements; however this is not the case in other countries. For example, ABET, the board responsible for American engineering accreditation, has had outcomes based requirements in full effect since 2001 [5]. The required outcomes can be clearly divided into two groups [6] - the "hard skills", such as sciences, design and analytical capability, and "professional skills", consisting of:

- An ability to function on multidisciplinary teams

- An understanding of professional and ethical responsibility

- An ability to communicate effectively

- The broad education necessary to understand the impact of engineering solutions in a global, economic, environmental, and societal context

- A recognition of the need for, and an ability to engage in lifelong learning

- A knowledge of contemporary issues

That these outcomes are required for successful and responsible professional engineering is clear, although some may argue as to where they should be learned. A recent research study [7] that surveyed over three hundred practicing engineers and over eight hundred upper year engineering students strongly suggests that many of these outcomes are high priority for 
employers, and therefore should be an essential part of formal engineering education.

Assessing multidisciplinary capability, team and communication skills or the degree to which students exhibit social responsibility and enhanced critical and creative thinking pose a new challenge for faculty finding and implementing a method of assessment that reflects and supports valued learning and skill processes as well as it does desired content outcomes. In a recent article succinctly entitled “ABET 'Professional Skills' - Can They Be Taught? Can They Be Assessed?" [8], the author discusses the difficulty and confusion in teaching and assessing these skills and attitudes which cannot be measured in traditional engineering assessment fashion. Quoting the author, "Recent assessment efforts directed at the professional skills could be best described as encouraging, but with much work left to do. ...the literature remains sparse with respect to robust, effective measures for these outcomes”. Clearly, there is need for effective assessment tools in professional skills education.

\section{APSC 190 - A Novel Approach to Teaching and Learning Professional Skills}

As a core element of its "Integrated Learning" engineering education philosophy [9], [10], [11], the Faculty of Applied Science at Queen's University recognizes professional skills as an integral requirement of an engineering student's formal education. Although such skills are commonly integrated as learning objectives in other courses (particularly capstone design courses), it was believed that professional skills should be identified separately and introduced early in order to emphasize their importance to students, and to provide the framework for continuing enhancement of these skills throughout the formal education. In the fall of 2003, the first offering of APSC 190 "Professional Engineering Skills" was introduced to the first year engineering class of approximately 600 students.

The key course objectives are:

- To provide students with a base on which to develop their approaches to learning

- To provide students the opportunity to "think like an engineer"

- $\quad$ To introduce students to engineering design process and project management

- To aid the students in developing "responseability” both personally and professionally

In terms of outcomes expectations, by the end of the course, it was expected that students will have developed their ability to:
- Manage their learning time

- Work well in teams and understand their role as a team player

- $\quad$ Plan projects efficiently and effectively

- Communicate effectively orally and in written form

- Access information from a variety of sources

- Demonstrate enhanced creative thinking

- Demonstrate sensitivity and inclusivity towards diversity

- Critique, analyse and synthesise environmental, liable, ethical, health and safety issues

- Demonstrate enhanced social responsibility

Designed by a team consisting of an expert in engineering education and three instructors with over fifty total-years of experience in engineering practice, the course was unique in almost every way. Course material was delivered through a one-week intensive series of facilitated workshops in groups of about 20 students, rather than through traditional didactic lectures. The workshops, including case studies based on actual engineering practice examples, were designed to be thought-provoking, controversial, and often included role-play. Facilitation was provided by a well-trained team of Teaching Assistants (TAs) consisting of graduate students from a broad range of studies including engineering, sociology, fine arts, history and others.

Following the active learning workshops in the first weeks, students worked the remainder of the term on a major team project, applying many of the principals discussed in the workshop sessions. Through such application on real and often controversial engineering topics (such as the construction of nuclear power stations or pesticide plants), deeper learning was encouraged.

A variety of deliverables - written, oral, and participatory - were required throughout the course. Students maintained and submitted a learning portfolio, weekly memos and formal reports, gave oral progress presentations, and were expected to contribute effectively and equitably to their team's project efforts. The assessment breakdown was designed to be both formative to provide ongoing feedback to enhance student learning, as well as summative, determining student grades based on both individual and team contributions.

\section{Assessment}

Initially, the SOLO taxonomy [4] was adopted as the framework within which assessment for APSC 190 was to be conducted. The taxonomy depicts learning as an evolution from novice to expert and, as such, 
resonated with many faculty members. Within the SOLO framework learning is viewed, not as the accumulation of discrete skills and bits of information but as a transformative process where learners "do different" rather than "do more" of what they were previously doing. The taxonomy was initially invaluable in that it provided a useful way for faculty members to conceptualize the changes they were planning for their students' learning. Unfortunately, the five levels of learning (prestructural; unistructral; multistructural; relational; and extended abstract) made it difficult to communicate expectations to students in a way that supported their learning. In fact, it began to become apparent that some students were becoming distracted, rather than assisted, by the framework. They were spending far too much time trying to decipher the assessment framework, time that could have been more productively spent on their coursework.

Another side effect of the relative inaccessibility of the SOLO taxonomy was that TAs for APSC 190 had considerable difficulty interpreting the model for use in grading assignments. Varying interpretations of student work in relation to the taxonomy resulted in inconsistent grading and lower than acceptable levels of inter-reader reliability among TAs and faculty.

The current literature in higher education indicates that what and how students choose to learn is largely influenced by what and how faculty members chose to assess [12] and that the assessment model in place has greater influence over students' learning than any other aspect of the curriculum [13]. Additionally, recent research indicates that students' achievement can be significantly improved through improving their understanding of the criteria and processes of assessment [14]. Taking the recent literature into consideration, it became critical to APSC 190 faculty that they find and implement a model of assessment that was consistent with their intentions to focus on learning and skills processes as well as on content and that also facilitated students' development as professional engineers in a qualitative way. Faculty members wanted to maintain the focus on the qualitative, rather than cumulative, aspects of learning that SOLO enabled but they also wanted something that was easier to communicate, understand and implement.

With the express purpose of condensing the cognitive transformative literature, of which SOLO is a part, into a portable, accessible model, Wilson [1] introduced ICE, an acronym for Ideas, Connections, and Extensions, three qualitatively different phases of learning. The model is portable in that it is easy to remember and is applicable to learning across domains and disciplines. It is accessible in that the vocabulary of the model makes it easy to share and understand. In short, the model is simple without being simplistic. Elaborating on the original model, Fostaty Young and Wilson [2] and later Fostaty Young [3] presented Ideas, Connections and Extensions (ICE) to represent three recurring phases in the evolution of learning and growth from a novice to expert state. Ideas represent the basics of early learning. They are the discrete skills and pieces of information that represent the fundamentals of new learning. Ideas include facts, vocabulary, definitions, discrete skills, or steps in a process. Any reiteration or recall of information, whether from a lecture, class notes or a textbook, is a demonstration of Ideas-based learning as is a demonstration of ability to follow a protocol. For example, with respect to the learning portfolios that were required as part of APSC 190, a student functioning primarily in Ideas would likely present a portfolio with the following characteristics:

- Offers a basic description (gives a list) of topics covered in classes each week, by providing a content list of course materials

- Uses classroom generated examples to demonstrate examples of what was learned Statements of personal opinions. ("I did ...,", "We learned ...", etc.)

Within the ICE framework, Connections have been characterized as being of two types: those made at the content level and those that represent personal meaning-making. Connections at the content level are demonstrated when students are able to articulate relationships among discrete Ideas and when they are able to convey how concepts within the course content are related to one another. So, when students are able to describe cause-effect relationships or when they are able to combine two or more discrete skills into a fluid, effective and efficient process, they are exhibiting Connections at the content level. Connections at the more personal meaning-making level are said to occur when students are able to relate their new learning to what they already know or have learned in other courses. It is in Connections that learning seems to take on qualitatively different characteristics than learning in Ideas. Here, learning becomes more easily retrievable by the student and longer term than the learning exhibited in Ideas. A Connections level response in the student learning portfolio is described using the following criteria:

- Addresses a focus question or problem, connecting topics by posing solutions to and reflections on materials learned in classes

- Connects ideas by supporting them with evidence drawn from classes 
- Recognizes indirect links, not necessarily contextual ("That is similar to ... ", "The reason might be ... ", "We learned it this way...", etc.)

When students are functioning at the level of Extensions, they are able to use their learning in novel and creative ways that are often quite removed from the original learning context. Here the learning has become internalized to the degree that it enables students to answer extrapolative questions, anticipate outcomes and alternatives to proposed situations and articulate implications. Extensions are sometimes referred to as the "so now what" phase of learning "So, now that you know what you know, what difference does it make to the way you now see the world"? Students who have reached Extensions are able to entertain, and answer, those types of questions. An Extensions level assessment in the student learning portfolio is described as:

- The writer demonstrates critical thinking.
- Applies material to unique situations, showing evidence of careful reflection and creativity

- Relates personal learning to other parts of the course, program and/or professional life ("If I applied that idea to...then ...”, “A better approach for me may be to... ", "I would predict that next time....", "I would have preferred to learn it this way...", etc,)

Notice that in each instance the rubric descriptors relate to the learning processes that students are encouraged to demonstrate. The focus is on what the student does with the content rather than focusing on the content alone. An example of the ICE rubric for assessment of the student learning portfolio is shown in Table 1. Note that while ICE rubrics may often incorporate a significant number of assessment elements, in this case, the learning objectives were focused only on content (in terms of relevance to learning objectives rather than volume) and clarity with respect to effective written communication.

Table 1. An example ICE rubric for assessment of student learning portfolios

\begin{tabular}{|c|c|c|c|}
\hline & $\begin{array}{c}\text { Ideas } \\
(50-64 \%)\end{array}$ & $\begin{array}{c}\text { Connections } \\
(65-79 \%)\end{array}$ & $\begin{array}{l}\text { Extensions } \\
(\mathbf{8 0 - 1 0 0 \% )}\end{array}$ \\
\hline Content & $\begin{array}{l}\text { - Offers a basic } \\
\text { description (gives a } \\
\text { list) of topics covered } \\
\text { in classes each week, } \\
\text { by providing a content } \\
\text { list of course materials } \\
\text { - Uses classroom } \\
\text { generated examples to } \\
\text { demonstrate examples } \\
\text { of what was learned } \\
\text { - Statements of personal } \\
\text { opinions. } \\
\text { "I did ...," } \\
\text { "We learned ...," etc. }\end{array}$ & $\begin{array}{l}\text { Addresses a focus question } \\
\text { or problem, connecting } \\
\text { topics by posing solutions to } \\
\text { and reflections on materials } \\
\text { learned in classes } \\
\text { - Connects ideas by } \\
\text { supporting them with } \\
\text { evidence drawn from classes } \\
\text { "That is similar to ..., ," } \\
\text { "The reason might be ..., ," } \\
\text { "We learned it this way...," } \\
\text { etc. }\end{array}$ & $\begin{array}{l}\text { The writer demonstrates critical } \\
\text { thinking. } \\
\text { - Applies material to unique } \\
\text { situations, showing evidence of } \\
\text { careful reflection and creativity } \\
\text { Relates personal learning to other } \\
\text { parts of the course, program } \\
\text { and/or professional life } \\
\text { "If I applied that idea to...then ....," } \\
\text { "A better approach for me may be } \\
\text { to... , " } \\
\text { "I would predict that next time....” } \\
\text { "I would have preferred to learn it } \\
\text { this way...," etc. }\end{array}$ \\
\hline Clarity & $\begin{array}{l}\text { Terminology and } \\
\text { concepts are clearly } \\
\text { defined } \\
\text { Makes accurate } \\
\text { statements about the } \\
\text { topics discussed } \\
\text { Logical, coherent } \\
\text { presentation of ideas } \\
\text { through writing } \\
\text { Writing does not } \\
\text { interfere with the } \\
\text { ability to convey ideas }\end{array}$ & $\begin{array}{l}\text { - Connects ideas to each other } \\
\text { connects classroom } \\
\text { concepts to external } \\
\text { situations or events } \\
\text { - Helps audiences make } \\
\text { connections to their own } \\
\text { situations } \\
\text { Writing enhances the } \\
\text { reader's ability to understand } \\
\text { the writer's thought process }\end{array}$ & $\begin{array}{l}\text { Extrapolates understanding to } \\
\text { new situations } \\
\text { Writing shows evidence of careful } \\
\text { consideration towards the } \\
\text { reader's ability to comprehend } \\
\text { the writer's personal learning }\end{array}$ \\
\hline
\end{tabular}


The simplicity of the ICE model and its accessible vocabulary simplified communication about intended learning outcomes for the course and about the assessment of those outcomes. The model was introduced as part of the TAs' two-day training session for the course that also included sessions on such topics as teamwork, creative problem-solving, ethics, liability and engineering projects. After a brief introduction to the assumptions about learning that are inherent to the ICE model, TAs had an opportunity to apply ICE to a series of learning journal entries. Their task was to identify the levels of learning that were expressed through the writing of the entry and then to provide feedback designed to nudge the student-writer toward deeper learning. They were also asked to assign grade levels based on the ICE rubrics that were provided. After several iterations with interspaced discussion on the methodology, grade levels assigned by 17 TAs on these journal entries typically fell within $+/-5 \%$, a remarkable achievement in consistency on such abstract entries.

Several beneficial effects of using ICE assessment were observed through the progression of the course. From a student perspective, the previous SOLO assessment method prompted a significant number of questions, and at times, challenges from students on both formative and summative assessment of course deliverables. Using the ICE methodology and corresponding rubrics, there appeared to be a much higher level of understanding of the assessment process resulting in very few, and only minor, challenges of summative assessment. This was further reinforced by a significant year-over-year reduction in (negative) student comments regarding assessment in course evaluation.

Further, by applying ICE rubrics that had been prepared for each student deliverable (e.g. weekly progress report, oral presentation, final report), students appeared to grasp the concept of achieving "connections" or "extensions" levels much easier than with SOLO nomenclature. Based on year-over-year experience of meeting with student teams to discuss formative feedback, ICE methodology significantly increased the level of student's understanding of learning expectations. Moreover, because the rubrics also provided qualitative descriptors of some possibilities for enhanced learning, students were able to adapt, plan for, and engage in deeper learning than they might otherwise have. The result of having more clearly articulated expectations was an increase in students' level of achievement.

It was noted by TAs and instructors that formative feedback could be provided to students more clearly by applying the ICE rubrics. Once familiar with the model's underlying concepts, differentiating Ideas,
Connections, and Extensions using context-based rubrics simplified the assessment process. In returning student's graded work, specific examples of ICE levels could be pointed out relatively easily. Similarly, the rubrics could be effectively used to guide students with descriptions and examples of deeper learning. In this respect, the rubrics served a valuable secondary purpose - supporting the development of students' self-assessment skills as they compared their current output with rubric descriptors.

Another interesting observation was a notable lower frustration level amongst TAs when using ICE assessment principles. In previous years while using SOLO-based assessment, extensive dialogue (email and verbal) amongst TAs and instructors during assessment phases was focused on issues related to difficulty in applying the taxonomy. In fact, the most consistent feedback comments from TAs at the end of previous iterations of the course were requests to improve the assessment process. In contrast, the introduction and application of the ICE assessment methodology resulted in very little inter-TA email traffic and very few assessment-related questions directed to (and amongst) instructors. TA feedback at the end of the first year using ICE methodology suggested only that some of the rubrics might benefit from additional descriptors for a few, specific categories. Overall, TAs were very satisfied with the process, particularly those who had participated in previous years, using SOLO.

Finally, the remarkable increase in grading consistency amongst TAs must be noted. In previous years, using the SOLO taxonomy as a guide, grade interpretations varied significantly among TAs. In some cases, instructor reviews of TA-assessed student deliverables required adjustments of as high as +/$15 \%$ in order to align grades more accurately with attainment of the stated learning criteria. In contrast, in a similar class size of nearly 600 students working in 6-7 person teams with 15 TAs providing facilitation and first-pass assessment, grading using ICE required little, if any, adjustment by instructors.

\section{Summary}

Several factors related to, but not directly attributed to, ICE contributed to the learning success of students in APSC 190. First, faculty members actively sought out a framework for assessment that accurately reflected their beliefs about how learning occurs. After having agreed that ICE was one such framework, they set out to describe, in qualitative terms, what learning "looks like" at various levels of expertise in the development of engineering professional skills. The 
next critical step was taken when faculty members used the easily accessible and meaningful language of ICE to share the department's conceptions of learning and expectations for student achievement with TAs and then with students. The framework for learning and the specificity of the communication about expectations for learning provided a common language through which to communicate about learning throughout the duration of the course. TAs and students alike internalized the message that learning isn't about accumulating more and more isolated bits of information as much as it is about combining those bits of information in meaningful ways that allow them to transform into something new.

The creation of rubrics for each course deliverable meant that through a process of contrasting their ongoing work against the outcome descriptors, students had a consistent means of engaging in self assessment and of getting formative feedback about their progress.

Once the ICE framework was adopted and articulated, faculty members, TAs and students had a comparably easier time recognizing the learning processes evident in work that was being produced. The key was in articulating conceptions of learning and in providing examples of what learning looks like in the development from novice to expert. The confidence that TAs developed in their ability to recognize demonstrations of Ideas, Connections, or Extensions-type learning processes translated to their increasing confidence and consistency in grading students' work. Second reading by instructors further reinforced this confidence, and validated the ICE methodology as an effective and reliable assessment process.

\section{References}

[1] Wilson, R. J, Assessing Students in Classrooms and Schools, Allyn \& Bacon, Scarborough, ON, 1996.

[2] Fostaty Young, S. and R.J. Wilson. Assessment and Learning: The ICE Approach. Portage and Main Press, Winnipeg, MB, 2000.

[3] S. Fostaty Young, “Teaching, Learning and Assessment in Higher Education: Using ICE to Improve Student Learning", Proceedings of the Improving Student Learning Symposium, London, UK, 2005 pp.105-115.

[4] Biggs, J. B. and K.F. Collis, Evaluating the Quality of Learning: The SOLO Taxonomy, Academic Press, New York, NY, 1982.
[5] ABET, Criteria for Accrediting Engineering Programs, Baltimore, Md.: Engineering Accreditation Commission, Nov. 11, 2003. See http://www.abet.org/criteria_eac.html

[6] Larry J. Shuman, "The ABET "Professional Skills" Can They Be Taught? Can They Be Assessed”, Journal of Engineering Education, ASEE, Washington, Jan 2005, pp. 41-55.

[7] Elizabeth E. May, "Education Meets Industry: A Study of the Capabilities of Engineering Graduates and the Expectations of Industry with Respect to Engineering Design and Related Skills, Master's Thesis, Queen's University, Kingston, Ontario, Canada, September 2006.

[8] S. Beyerlein, D. Davis, M. Trevisan, P. Thompson, and O. Harrison, "Assessment Framework for Capstone Design Classes”, Proceedings from the Society for Engineering Education Annual Conference, ASEE, Chicago, June 2006.

[9] James D. McCowan and Christopher K. Knapper, “An Integrated and Comprehensive Approach to Engineering Curricula Part One: Objectives and General Approach”, International Journal of Engineering Education, TEMPUS Publications, Dublin, 2002, pp. 633-637.

[10] James D. McCowan, “An Integrated and Comprehensive Approach to Engineering Curricula Part Two: Techniques", International Journal of Engineering Education, TEMPUS Publications, Dublin, 2002, pp. 638643.

[11] David S. Strong and James D. McCowan, "Effective Workspace for Engineering Education: The Integrated Learning Centre at Queen's University in Kingston”, Proceedings from the $1^{\text {st }}$ Annual CDIO Conference, Queen's University, Kingston, Ontario, Canada, June 2005.

[12] Ramsden, P, Learning to Teach in Higher Education, Routledge, New York, NY, 1992.

[13] D. Boud, "Assessment and the promotion of academic values”, Studies in Higher Education, 1990, pp. 101-111.

[14] C. Rust, M. Price, and B. O’Donovan, "Improving Students' Learning by Developing their Understanding of Assessment Criteria and Processes”, Assessment and Evaluation in Higher Education, 2003, pp. 148-164. 